\title{
Medical Therapy of Perianal Crohn's Disease
}

\author{
Thomas Klag ${ }^{a}$ Martin Goetz ${ }^{a}$ Eduard F. Stange ${ }^{b}$ Jan Wehkamp ${ }^{a}$ \\ a Department of Internal Medicine I, University of Tübingen, Tübingen, Germany, \\ ${ }^{b}$ Department of Internal Medicine I, Robert-Bosch-Hospital, Stuttgart, Germany
}

\section{Keywords}

Inflammatory bowel disease - Crohn's disease .

Perianal fistula - Anti-TNF-alpha therapy .

Crohn's disease complications

\section{Summary}

Background: Development of perianal fistulas are a common feature of Crohn's disease (CD). Consequences are severe impairment of quality of life as well as potentially life-threatening complications like abscess formation or bacterial sepsis. Therefore, appropriate treatment is an important task in the management of CD. Methods: This review describes the epidemiology, pathogenesis, diagnosis, and conservative medical treatment of perianal $C D$ with regard to the available literature. In February 2015, a PubMed search was performed with the following terms (combined and separate): 'Crohn's disease management', 'Crohn's disease complications', 'perianal Crohn's disease', 'fistulizing Crohn's disease', 'perianal fistulas', 'fistula healing', 'fistula closure'. From the search results, 36 articles were chosen as core elements of this review. Results: Pelvic magnetic resonance imaging and rectal endosonography are established diagnostic approaches to evaluate perianal fistulas in conjunction with endoscopy. Antibiotics, thiopurines, and calcineurin inhibitors are useful agents in the management of perianal CD. The availability of anti-TNF-alpha therapies has substantially changed the prospects and goals of medical treatment, and fistula healing seems to be possible in a substantial proportion of patients. Conclusion: Antibiotics and several immunosuppressive drugs have improved the treatment of fistulizing $C D$ and should be combined with surgical measures.

(c) 2015 S. Karger GmbH, Freiburg

\section{Introduction}

Crohn's disease (CD) is characterized by inflammatory mucosal lesions which can affect all regions of the gastrointestinal tract [1]. Furthermore, the development of fistulas is a prominent feature of CD. Fistulas can be found between different bowel segments (interenteric), between the intestine and other organs (e.g. entero-vesical), between the intestine and the skin (entero-cutaneous), and as manifestation of rectal involvement of CD with the appearance of perianal fistulas. In patients with large bowel involvement of $\mathrm{CD}$, especially in those with rectal involvement, a higher incidence of perianal fistulas can be observed compared to patients without colonic involvement [2]. The prevalence of perianal fistulas depends on the respective general disease location. Patients with isolated ileal CD develop perianal fistulas in only $12 \%$; in ileo-colonic disease the prevalence is $15 \%$, in colonic disease without rectal involvement $41 \%$, and in colorectal disease it rises up to $92 \%$ [3]. In about $10 \%$ of patients, perianal fistulas can be found as first manifestation of CD before other symptoms become apparent. Formation of perianal fistulas therefore can precede the onset of Crohn's disease by several years [3]. Openings of perianal fistulas mostly involve the perianal skin; however, openings in the groin, vulva, and scrotum are also observed [4]. Perianal fistulas are described in $17-50 \%$ of CD patients in population-based studies $[3,5]$. According to the epidemiological data of Schwartz et al. [5], about one third of CD patients will develop a minimum of one fistula in their lifetime. In most cases (about two third), these fistulas will be external, with $55 \%$ being perianal and about $6 \%$ being entero-cutaneous. About one third are internal fistulas [5]. These data underline the role of perianal fistulas as a common complication in CD.

Perianal fistulas often cause severe impairment of a patient's quality of life, with perianal pain, swelling, spontaneous drainage of pus, stool or blood from the fistula's opening, and fever in the case of abscess formation. Severe complications can arise if abscesses lead to bacterial sepsis. Therefore, appropriate treatment is an important task in the management of CD. The aim of every

\section{KARGER \\ Fax +497614520714

Prof. Dr. med. Jan Wehkamp

Department of Internal Medicine I

University Hospital Tübingen

Otfried-Müller-Straße 10, 72076 Tübingen, Germany

Jan.Wehkamp@med.uni-tuebingen.de 
therapy is the resolution of secretory activity to improve quality of life, the prevention of septic complications, and, if possible, fistula closure [6].

Therapy of perianal fistulas should be based on an interdisciplinary approach combining surgical as well as medical treatment. Especially complicated fistulas with development of abscesses require close interdisciplinary management. The surgical treatment is described by Kreis et al. [7] in this issue, and both treatment approaches - surgical and/or conservative - should be considered depending on the clinical situation. However, in this article, we will focus on the medical conservative treatment options for the management of perianal CD after a short description of the pathogenesis and diagnostic approaches.

\section{Pathogenesis of Fistulas in Crohn's Disease}

To understand the possible benefit of medical treatment options in fistulizing $\mathrm{CD}$, it is important to describe the pathophysiology of fistula formation. However, fistula pathogenesis is still poorly understood. A multi-step pathogenesis seems to be the most comprehensive explanation. In CD pathogenesis, genetically and environmentally driven disturbances in the antimicrobial barrier of the gut against millions of bacterial commensals and pathogens seem to trigger mucosal injury and inflammation [8]. This inflammatory tissue destruction leads to a transmural tissue-overarching defect in the gut wall, which can be histologically characterized as tissue injury penetrating into the deep layers of the intestine [2, 9]. Mucosal fibroblasts, responsible for tissue healing, seem to have less migratory potential in $\mathrm{CD}$ patients than fibroblasts of healthy controls. Therefore, as one possible explanation, appropriate wound healing does not take place $[2,10]$. Instead, these fissure-like tissue defects are characterized by epithelialization as an alternative healing mechanism of the intestinal barrier $[9,11,12]$. Furthermore, bacterial colonization seems to be involved in the formation and perpetuation of fistulas. In perianal fistulas, skin-derived bacteria seem to remarkably be the main involved microorganisms, rather than gutderived bacterial flora $[6,13]$. Keeping these pathomechanistic interrelations in mind, therapeutic approaches need to include on the one hand modulation of the inflammatory processes leading to fistula formation and on the other hand antibacterial strategies to decrease the bacterial burden aggravating inflammatory cascades.

\section{Diagnostic Approaches}

Diagnostic procedures have the aim to determine the distinct location and extent of perianal fistulas as well as their anatomical position. Endoscopy is routinely performed early in the workup for fistulizing Crohn's disease and will not be discussed in detail here. Importantly, downstream strictures need to be ruled out since these significantly interfere with fistula healing by obstructing the natural 'way of least resistance' and deviate the fecal stream to pass through the fistula tract (fig. 1).
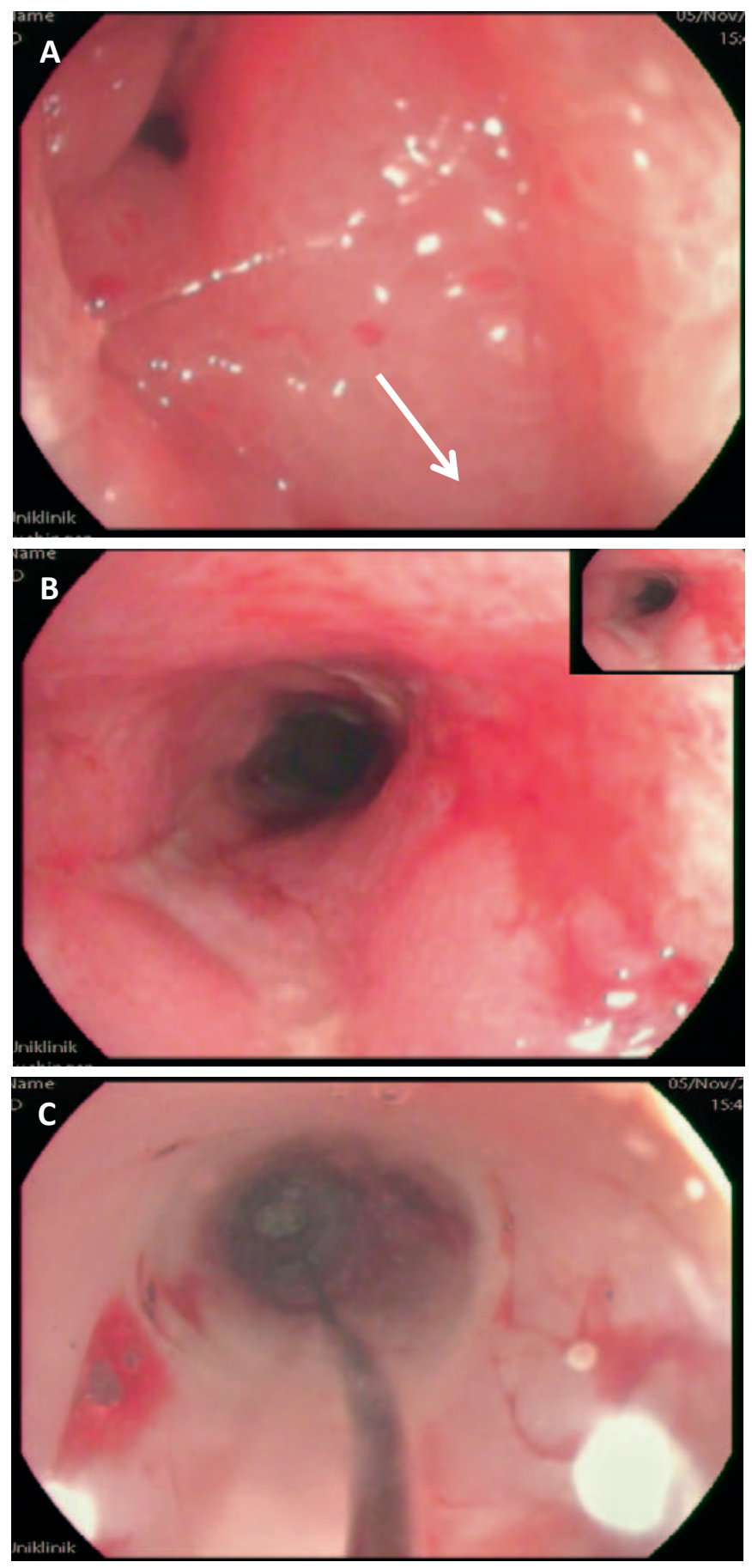

Fig. 1. A Distal (perianal) orifice of a fistula tract, gastrointestinal lumen at 5 o'clock (arrow). B Anorectal stenosis with stigmata of chronic inflammation (ulceration and wall thickening). C Balloon dilatation of the intestinal stenosis to promote fistula healing in addition to medical therapy.

Furthermore, complications like abscesses or organ penetration need to be evaluated [14]. To this end, imaging techniques like fistulography, computed tomography, anorectal endosonography (EUS), and pelvic magnetic resonance imaging (MRI) are potential methods in principal; however, since fistulography and computed tomography provide very low diagnostic accuracy combined with radiation exposure, these methods are no longer in clinical use nor recommended $[6,14]$, and pelvic MRI and anorectal EUS have become the 


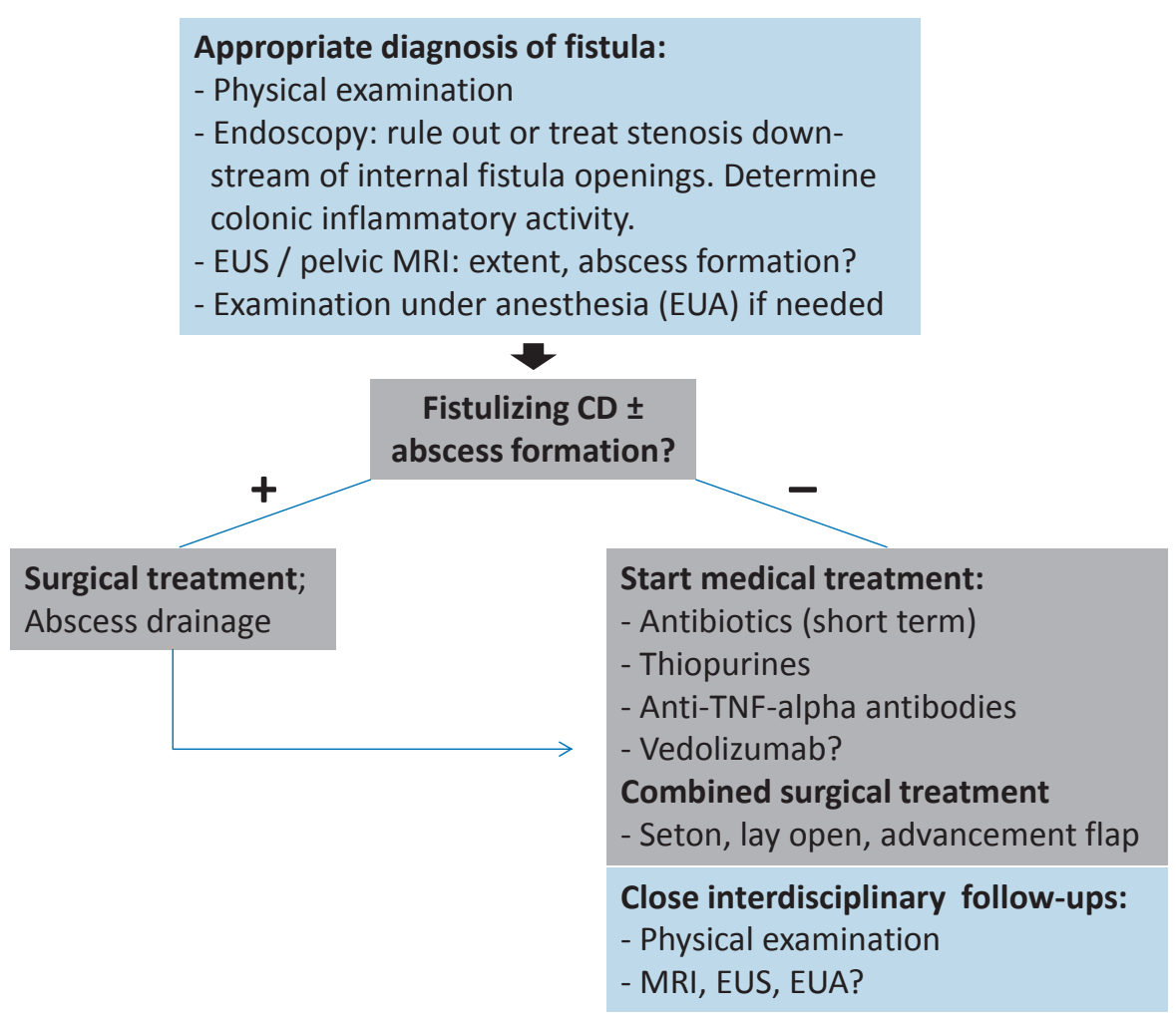

Fig. 2. Diagnostic and therapeutic algorithm for the management of perianal Crohn's disease.

methods of choice. Naturally, physical examination is mandatory as a first step to determine the presence of perianal lesions (e.g. ulcers), the extent of skin alterations, signs of abscess formation, and the number and active secretion status of external fistula openings. Endoscopic examination should be performed to determine rectal and colonic inflammatory activity (fig. 2) [14]. In the following section, advantages and disadvantages of EUS and MRI will be discussed.

\section{Rectal Endosonography}

High-frequency EUS is able to visualize internal sphincteric structures, and especially with hydrogen peroxide installation it is possible to identify and characterize fistula tracts [15, 16]. A 2012 meta-analysis from Siddiqui et al. [17] revealed a sensitivity of $87 \%$ for fistula detection whereas specificity reached only $43 \%$. Even though EUS is widely available and carries limited costs, its diagnostic potential is strongly operator-dependent and the full spectrum of its benefits can only be achieved in the hands of an experienced examiner. Technical limitations are the impossibility of its use in anal stenosis and the limited assessment of the external sphincter [6]. In the case of complex fistula systems, tracks might be outside the diagnostic window of this method [13].

\section{Pelvic Magnetic Resonance Imaging}

Pelvic MRI is an accurate method of detecting fistula tracts and abscesses and their relation to neighboring anatomical struc- tures, and is able to differentiate between inflammatory activity versus fibrotic fistula tracks $[18,19]$. The above-mentioned metaanalysis by Siddiqui et al. [17] also investigated the sensitivity and specificity of fistula detection by pelvic MRI with values of 87 and $69 \%$, respectively. Pelvic MRI has a high accuracy in detecting abscess formation. Figure 1 depicts an example of a severe perianal fistula system with pararectal abscess formation that was treated with radiologically guided drainage placement prior to antitumor necrosis factor (TNF)-alpha therapy (fig. 3). As Schwartz et al. [20] found comparable accuracy of EUS and pelvic MRI (91 and $87 \%$ ), the use of each technique depends on expertise and patient preferences. However, a study published in 2004 by Buchanan et al. [21] revealed superiority of MRI compared to EUS with respect to classification and identification of fistula tracts as well as abscesses. However, costs are higher for pelvic MRI compared to EUS [14].

Another established method of investigating perianal fistulas is examination under anesthesia (EUA) by an experienced colorectal surgeon. The major advantage of this method is the direct possibility to place a seton stitch and to drain abscesses. Accuracy is comparable to that of MRI and EUS at approximately 90\% [20].

\section{Medical Treatment of Perianal Crohn's Disease}

Several immunosuppressive and immune-modulatory therapies have been evaluated concerning treatment of perianal fistulas. Not all of them proved efficacious. Mesalazine (5-aminosalicylic acid) did not show any effect on perianal fistula healing [2]. Also corti- 

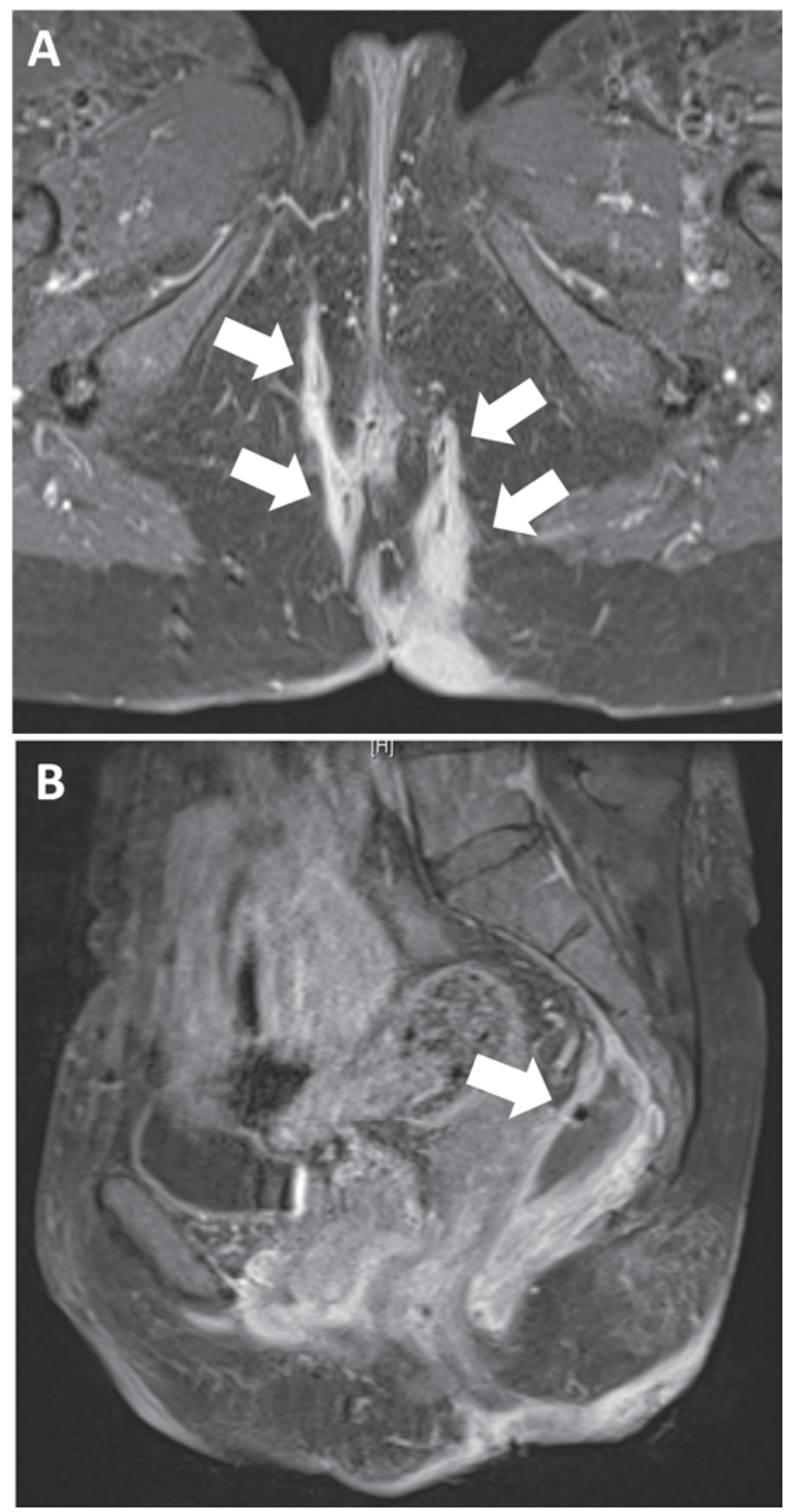

Fig. 3. Magnetic resonance imaging (MRI) scan of perianal fistulas in a patient with Crohn's disease. A Arrows indicate complex fistula tracks. B Arrow indicates a big pararectal abscess that was treated by computed tomographyguided drainage 1 day later, before anti-TNF-alpha therapy with infliximab was initiated. MRI imaging with the kind assistance of Prof. Niolaou and PD Dr. C. Schraml, Department of Radiology, University of Tübingen.

costeroids have no positive effects on fistula healing and may even have harmful properties. Increased rates of complications have been reported, accompanied by an increased need for surgery [4, 22, 23]. Therefore, corticosteroids cannot be recommended in the setting of perianal fistulas in $\mathrm{CD}$.

Furthermore, one has to keep in mind that spontaneous fistula healing is also possible. From the data pool of placebo-controlled clinical trials evaluating the efficacy of multiple therapeutic ap- proaches, the spontaneous fistula closing rate (placebo rate) seems to be between 6 and 13\% [24, 25]. Therefore, every therapeutic approach needs to be better than that, without raising the rate of complications.

Antibiotics, calcineurin inhibitors (CNIs), thiopurines, and anti-TNF-alpha therapy are established therapeutic options and will be discussed in the following sections. New agents like the anti-integrin antibody vedolizumab might also have the potential to modulate the natural course of perianal fistulizing $\mathrm{CD}$.

In any case, all therapeutic approaches should focus on prevention of septic complications arising from perianal abscess formation. Therefore, before starting one of the above immunosuppressive agents, abscess formation needs to be ruled out and existing abscesses treated by drainage/surgery and/or antibiotics (fig. 2) [14]. This applies especially to anti-TNF-alpha therapy, as severe septic complications can be the result of inadequate abscess control.

\section{Antibiotics (Ciprofloxacin/Metronidazole)}

The significance of antibiotics in the treatment of perianal CD lies in first-line management as well as the management of infectious complications; however, no frequent and sustained healing has so far been reported with antibiotic treatment alone [4]. Metronidazole is the best studied antibiotic in perianal $\mathrm{CD}$ even though evidence is widely based on only three studies [26-28]. Clinical improvement on metronidazole treatment can be expected within 6-8 weeks [26]. The fistula closure rate has been shown to be approximately $50 \%$ [28]. However, fistula healing seems to not be sustained. 4 months after cessation of metronidazole treatment, the recurrence rate is about $80 \%$ [27]. Unfortunately, long-term use of metronidazole is associated with side effects such as a metallic taste in the mouth, dyspepsia, and peripheral neuropathy [24]. Therefore, metronidazole seems to not be suitable for long-term use in perianal CD (table 1).

Ciprofloxacin has also been investigated in perianal CD, albeit in only just two small studies. $80-100 \%$ of patients in these small case series showed fistula improvement $[29,30]$. However, longterm use is associated with nausea, diarrhea, headache, and tendon rupture [24].

The combination of ciprofloxacin and metronidazole showed clinical response within 12 weeks of treatment in about $60 \%$ of patients with severe complex fistulas, and $20 \%$ even showed fistula closure. However, again no sustained response was observed, with symptom recurrence after treatment cessation [31]. The head-tohead comparison of ciprofloxacin versus metronidazole in a very small study (25 patients) suggested superiority of ciprofloxacin versus metronidazole, as $30 \%$ of patients treated with ciprofloxacin had fistula closure versus $0 \%$ in the metronidazole group after 10 weeks of treatment (12.5\% placebo group). Furthermore, termination of therapy before week 10 occurred in $71.4 \%$ in the metronidazole group versus $10 \%$ in the ciprofloxacin group [32]. However, because of the small sample size, further studies are needed. 
Table 1. Summary of the available Crohn's disease (CD) therapeutics and their role in the treatment of perianal fistulas

\begin{tabular}{|c|c|c|c|c|}
\hline CD therapeutics & $\begin{array}{l}\text { Positive influence on } \\
\text { fistula activity? }\end{array}$ & Short-term efficacy? & $\begin{array}{l}\text { Feasible for } \\
\text { long-term use? }\end{array}$ & $\begin{array}{l}\text { Fistula recurrence after } \\
\text { discontinuation? }\end{array}$ \\
\hline 5-ASA & no & no & - & - \\
\hline Corticosteroids & no & no & no & - \\
\hline Antibiotics (ciprofloxacin/metronidazole) & yes & yes & no & yes \\
\hline Calcineurin inhibitors & yes & yes & no? & yes \\
\hline Thiopurines & yes & after 3 months & yes & $-?$ \\
\hline Anti-TNF-alpha antibodies & IFX/ADA yes; CERT? & IFX/ADA yes; CERT? & yes & yes, in a proportion of patients \\
\hline Vedolizumab & yes & $?$ & yes & $?$ \\
\hline
\end{tabular}

IFX = Infliximab; ADA = adalimumab; CERT = certolizumab.

\section{Calcineurin Inhibitors (Tacrolimus/Cyclosporine)}

In general, CNIs have no significance in the treatment of nonfistulizing CD [33]. However, a number of studies have described efficacy of CNIs like cyclosporine and tacrolimus in fistulizing CD. As with antibiotics, short-term efficacy seems to be good, but fistula recurrence is one of the major concerns after CNI discontinuation [2]. Intravenous cyclosporine achieves a response in $88 \%$ of patients, and fistula closure can be found in $44 \%$ [34]. These results were widely confirmed in additional studies $[35,36]$. However, this benefit should be carefully weighed against potential side effects such as hypertension, tremor, seizures, renal failure, and septic complications [37]. Tacrolimus was investigated in one randomized placebo-controlled trial published in 2003 by Sandborn et al. [38]. Significant improvement in terms of narrowing of fistulas for more than 4 weeks was observed in $43 \%$ patients compared to $8 \%$ in the placebo group. Notably, the rate of fistula closure was comparable between the two groups (placebo, $8 \%$; tacrolimus, $10 \%)$. Serious adverse events were reported in the group of patients who received tacrolimus, which where managed by dose reduction. However, lower doses might be ineffective and need to be assessed in further trials [38]. In 10 patients studied by Gonzalez-Lama et al. [39], 40-50\% clinical response could be found with long-term treatment (6-24 months). Again, this needs to be weighed against potential side effects which are comparable to those described for cyclosporine.

\section{Thiopurines (Azathioprine/6-Mercaptopurine)}

The thiopurines azathioprine (AZA) and 6-mercaptopurine (6-MP) are established therapeutics for the induction and maintenance of remission in luminal CD [40]. A meta-analysis investigated five randomized trials of AZA and 6-MP, in which fistula response was assessed as secondary endpoint. The response rate was $54 \%$ in the treatment arms (AZA or 6-MP) and only $21 \%$ in the placebo arms [41]. Also complete fistula resolution can be observed with 6-MP as described by Present et al. [42]. In their patient cohort, $31 \%$ achieved fistula closure compared to $6 \%$ under placebo treatment. As is well-known, response to thiopurines is delayed, and often more than 3 months of treatment are needed to achieve clinical improvement. Even if fistula closure is infrequent, thiopurines seem to be effective in the treatment of perianal CD in terms of clinical improvement and symptom relief especially in the long term (table 1). Side effects such as pancreatitis, allergic reactions, infections, leucopenia, and drug-induced hepatitis need to be monitored closely [40].

\section{Anti-TNF-Alpha Therapy (Infliximab/Adalimumab/ Certolizumab)}

The introduction of anti-TNF-alpha antibodies has remarkably improved the therapy of perianal CD. The available anti-TNFalpha agents infliximab, adalimumab, and certolizumab have clearly demonstrated efficacy in this setting [6].

The first anti-TNF-alpha agent tested in a placebo-controlled study was infliximab. Present et al. [43] found in 68\% of 94 investigated patients clinical fistula improvement $(5 \mathrm{mg}$ infliximab per $\mathrm{kg}$ body weight; weeks $0,2,6$ ) versus $26 \%$ in the placebo group. In $55 \%$ of patients, fistula closure could be observed versus $13 \%$ in the placebo group. The median time to response was about 2 weeks, and fistulas remained closed for approximately 3 months (median duration of response). The ACCENT II trial confirmed these results in terms of efficacy of infliximab as maintenance therapy in perianal CD. $90 \%$ of 282 patients included in this study had perianal fistulizing CD. Patients received induction therapy at weeks 0 , 2 , and 6 , and then every 8 weeks ( $5 \mathrm{mg} / \mathrm{kg}$ ). $69 \%$ responded to the therapy (assessed at weeks 10 and 14). After 54 weeks, $46 \%$ of patients in the infliximab arm versus $23 \%$ in the placebo arm had a sustained response [44]. Hence, infliximab is feasible for induction and maintenance therapy of perianal CD. However, despite these favorable results, abscess development was observed during infliximab treatment in about $10-15 \%$ of cases. External fistula closure might be responsible for this phenomenon. Seton stitch placement can prevent this complication [24], and cumulative infliximab doses do not increase the risk of abscess development [45].

Adalimumab was tested in the CHARM study published in 2007. $30 \%$ of 113 studied patients with perianal fistulas showed fistula closure after 26 weeks of adalimumab treatment compared to 
placebo (13\% closure rate). An effect was also seen after 56 weeks (33 vs. 13\%) [46]. The CHOICE trial revealed similar results. Adalimumab achieved complete fistula healing accompanied by improved quality of life in $39 \%$ of patients who had previously failed to respond to infliximab therapy [47]. However, two trials did not show superiority of adalimumab to placebo. In the CLASSIC-1 trial [48] and the GAIN study [49], no significant differences could be found between placebo and treatment arms regarding fistula healing. Nevertheless, adalimumab seems to be an effective drug in distinct patient populations. According to the available literature, induction doses of 160 or $80 \mathrm{mg}$ followed by 80 or $40 \mathrm{mg}$ at week 2 followed by a maintenance dose of $40 \mathrm{mg}$ every other week is recommended [2].

Certolizumab is a humanized anti-TNF antibody with a pegylated Fab fragment, and has been evaluated in $\mathrm{CD}$ in the PRECiSE 1 and 2 studies [50, 51]. In both studies, fistula closure was not significantly different between placebo and certolizumab treatment groups. However, in a subgroup analysis of the PRECiSE 2 study, 58 patients with CD fistulas (55 perianal fistulas) with prior improvement on certolizumab induction therapy (defined as $>100$-point reduction in the Crohn's disease activity index) were randomized to receive either certolizumab maintenance therapy or placebo. At week 26, fistula healing was observed in $36 \%$ of the treatment group versus $17 \%$ of the placebo group $(p=0.038)$ [52]. Hence, the role of certolizumab in the treatment of perianal fistulas is somewhat elusive.

\section{Combination Therapies}

Several combination regimens of the drugs discussed above have been investigated. Selected trials are presented in the following section.

\section{Infliximab and Ciprofloxacin}

The combination of infliximab and ciprofloxacin was investigated in a placebo-controlled trial [53]. In this study, all patients received infliximab with randomized arms with additional ciprofloxacin treatment or placebo. The results showed no significant superiority of ciprofloxacin, even though by trend response to therapy was pronounced in the ciprofloxacin group compared to placebo.

\section{Adalimumab and Ciprofloxacin}

Recently, Dewint et al. [54] investigated the combination of ciprofloxacin and adalimumab in $76 \mathrm{CD}$ patients with perianal fistulas. Clinical response was defined as $50 \%$ reduction in active fistulas. Adalimumab was dosed at 160 and $80 \mathrm{mg}$ weeks 0 and 2 followed by $40 \mathrm{mg}$ every other week combined with ciprofloxacin $500 \mathrm{mg}$ or placebo twice daily. After 12 weeks, $71 \%$ of patients in the ciprofloxacin group showed a clinical response versus $47 \%$ in the placebo group. Furthermore, fistula closure was 65 versus 33\%, respectively. In a further 12 weeks of follow-up, only adalimumab was continued in both groups. As a result, the positive effect of ciprofloxacin on clinical response was lost, without any differences between ciprofloxacin and placebo treatment groups. Therefore, ciprofloxacin combined with adalimumab is more effective than adalimumab alone, an effect rapidly lost after antibiotic discontinuation.

\section{Thiopurines and Ciprofloxacin/Metronidazole}

The positive effects of antibiotics on fistula healing are often lost after discontinuation of therapy. Therefore, the combination of ciprofloxacin/metronidazole and thiopurines seem to be a promising approach to cater for the transition from combined induction therapy to long-term thiopurine therapy. Dejaco et al. [55] investigated this drug combination and found that $48 \%$ of patients treated with thiopurines and antibiotics showed clinical response after 20 weeks of treatment, compared to $15 \%$ of patients treated with antibiotics only $(\mathrm{p}=0.03)$. Along these lines, combinations of antibiotics and thiopurines are useful in the treatment of fistulizing $\mathrm{CD}$ and might provide a smooth transition from initial combined therapy to successful long-term therapy with thiopurines.

\section{Thiopurines and Anti-TNF-Alpha Therapy}

Tozer et al. [56] investigated 41 patients with perianal fistulas treated with infliximab or adalimumab and thiopurines over a period of 3 years. $58 \%$ of all patients demonstrated at least clinical response. $33 \%$ in the infliximab group could be defined as being in clinical remission. Most interestingly, clinical remission could be detected far earlier (median 12 months) than radiological healing. All patients with radiological healing while on infliximab therapy remained in remission during the study period. However, loss of response was possible if anti-TNF-alpha therapy was discontinued. No severe septic or infectious complications were detected, even though perianal abscesses occurred in 14 patients. Hence, the combination of anti-TNF-alpha antibodies and thiopurines seems to be effective and save in perianal CD.

\section{Anti-Integrin Antibody Therapy (Vedolizumab)}

A newly launched drug for the treatment of CD and ulcerative colitis is the anti-integrin antibody vedolizumab (Entyvio ${ }^{\circledR}$; Takeda, Taastrup, Denmark). Vedolizumab exerts its therapeutic activity by blocking the interaction of the alpha4-beta7 integrin with MAdCAM-1 which is expressed on endothelial cells. Through this mechanism, the inflammatory triggered migration of T-lymphocytes into the mucosal tissue is specifically blocked. In the GEMINI II and III studies on CD, vedolizumab was shown to achieve clinical response and clinical remission in moderately to severely active CD [57]. However, the influence of vedolizumab on perianal fistulas needs to be investigated in future trials (table 1). From a mechanistic point of view, hindrance of T-lymphocyte migration into the gut wall seems to be a promising strategy for fistula treatment, considering the pathogenesis of CD fistula formation. 


\section{Conclusion}

Management of perianal fistulas is still a major concern in the treatment of $\mathrm{CD}$, as quality of life is clearly influenced by this issue. Furthermore, septic complications because of uncontrolled abscess formation can be severely life-threatening. Therefore, the treatment of perianal fistulas should follow an interdisciplinary approach, with surgery being essential for drainage of fistula tracks and abscess treatment (see also Kreis et al. [7] in this issue). However, with the availability of anti-TNF-alpha therapies, medical treatment options have substantially changed the prospects and goals of perianal fistula therapy, with fistula healing seemingly possible in a substantial proportion of patients. Unfortunately, healing rates with medical treatment are still below $50 \%$ on average, and true healing is rarely achieved with fistula tracts persisting in the majority of cases. Innovative therapeutic strategies are therefore strongly needed. Vedolizumab might be a new promising agent in this setting, even though data regarding its influence on perianal CD are pending.

\section{Disclosure Statement}

No funding was received for this article. E.F. Stange received honoraria from Falk Pharma, AbbVie, Ferring, and Ardeypharm, and consultancy fees from Merck and Takeda. J. Wehkamp received honoraria from Falk Pharma, AbbVie, Ferring, Ardeypharm, MSD, Novartis, Takeda, Roche, and BoehringerIngelheim. T. Klag received honoraria from MSD. M. Goetz received speaker's honoraria from Falk Foundation, AbbVie, MSD, and Takeda, and consultancy fees from MSD.

\section{References}

1 Fakhoury M, Negrulj R, Mooranian A, Al-Salami H: Inflammatory bowel disease: clinical aspects and treatments. J Inflamm Res 2014;7:113-120.

2 Nielsen OH, Rogler G, Hahnloser D, Thomsen O: Diagnosis and management of fistulizing Crohn's disease. Nature Clin Pract Gastroenterol Hepatol 2009;6: 92-106.

3 Hellers G, Bergstrand O, Ewerth S, Holmström B: Occurrence and outcome after primary treatment of anal fistulae in Crohn's disease. Gut 1980;21:525-527.

4 Vavricka SR, Rogler G: Fistula treatment: the unresolved challenge. Dig Dis 2010;28:556-564.

5 Schwartz DA, Loftus EV Jr, Tremaine WJ, Panaccione R, Harmsen WS, Zinsmeister AR, Sandborn WJ: The natural history of fistulizing Crohn's disease in Olmsted County, Minnesota. Gastroenterology 2002;122: 875-880.

6 Marzo M, Felice C, Pugliese D, Andrisani G, Mocci G, Armuzzi A, Guidi L: Management of perianal fistulas in Crohn's disease: an up-to-date review. World J Gastroenterol 2015;21:1394-1403.

7 Seifarth C, Kreis ME, Gröne J: Indications and specific surgical techniques in Crohn's disease. Viszeralmedizin 2015;31:273-279.

8 Klag T, Stange EF, Wehkamp J: Defective antibacterial barrier in inflammatory bowel disease. Dig Dis 2013; 31:310-316.

9 Bataille F, Klebl F, Rümmele P, et al: Morphological characterisation of Crohn's disease fistulae. Gut 2004; 53:1314-1321.

10 Leeb SN, Vogl D, Gunckel M, Kiessling S, Falk W, Wild PJ, Fürst A, Hofstädter F, Schölmerich J, Herfarth H, Rogler G: Reduced migration of fibroblasts in inflammatory bowel disease: role of inflammatory mediators and focal adhesion kinase. Gastroenterology 2003;125:1341-1354.

11 Tarnawski AS: Cellular and molecular mechanisms of gastrointestinal ulcer healing. Dig Dis Sci 2005;50:24-33.

12 Dignass AU: Mechanisms and modulation of intestinal epithelial repair. Inflamm Bowel Dis 2001;7:68-77.

13 West RL, Van der Woude CJ, Endtz HP, Hansen BE, Ouwedijk M, Boelens HA, Kusters JG, Kuipers EJ: Perianal fistulas in Crohn's disease are predominantly colonized by skin flora: implications for antibiotic treatment? Dig Dis Sci 2005;50:1260-1263.

14 Gecse K, Khanna R, Stoker J, Jenkins JT, Gabe S, Hahnloser D, D'Haens G: Fistulizing Crohn's disease: diagnosis and management. United European Gastroenterol J 2013;1:206-213.
15 Law PJ, Bartram CI: Anal endosonography: technique and normal anatomy. Gastrointest Radiol 1989;14: 349-355.

16 Navarro-Luna A, Garcia-Domingo MI, Rius-Macias J, Marco-Molina C: Ultrasound study of anal fistulas with hydrogen peroxide enhancement. Dis Colon Rectum 2004;47:108-114.

17 Siddiqui MR, Ashrafian H, Tozer P, Daulatzai N, Burling D, Hart A, Athanasiou T, Phillips RK: A diagnostic accuracy meta-analysis of endoanal ultrasound and MRI for perianal fistula assessment. Dis Colon Rectum 2012;55:576-585

18 Haggett PJ, Moore NR, Shearman JD, Travis SP, Jewell DP, Mortensen NJ: Pelvic and perianal complications of Crohn's disease: assessment using magnetic resonance imaging. Gut 1995;36:407-410.

19 Halligan S, Stoker J: Imaging of fistula in ano. Radiology 2006;239:18-33.

20 Schwartz DA, Wiersema MJ, Dudiak KM, Fletcher JG, Clain JE, Tremaine WJ, Zinsmeister AR, Norton ID, Boardman LA, Devine RM, Wolff BG, Young-Fadok TM, Diehl NN, Pemberton JH, Sandborn WJ: A comparison of endoscopic ultrasound, magnetic resonance imaging and exam under anesthesia for evaluation of Crohn's perianal fistulas. Gastroenterology 2001;121: 1064-1072.

21 Buchanan GN, Halligan S, Bartram CI, Williams AB, Tarroni D, Cohen CR: Clinical examination, endosonography and MR imaging in preoperative assessment of fistula in ano: comparison with outcome-based reference standard. Radiology 2004;233:674-681.

22 Sparberg M, Kirnser JB: Long-term corticosteroid therapy for regional enteritis: an analysis of 58 courses in 54 patients. Am J Dig Dis 1966;11:865-880.

23 Malchow H, Ewe EK, Brandes JW, Goebell H, Ehms H, Sommer H, Jesdinsky H: European Cooperative Crohn's Disease Study (ECCDS): results of drug treatment. Gastroenterology 1984;86:249-266.

24 Bressler B, Sands BE: Review article: medical therapy for fistulizing Crohn's disease. Aliment Pharmacol Ther 2006;24:1283-1293.

25 Pascua M, Su C, Lewis JD, Brensinger C, Lichtenstein GR: Meta-analysis: factor predicting post-operative recurrence with placebo therapy in patients with Crohn's disease. Aliment Pharmacol Ther 2008;28:545-556.

26 Bernstein LH, Frank MS, Brandt LJ, Boley SH: Healing of perianal Crohn's disease with metronidazole. Gastroenterology 1980;79:357-365.
27 Brandt LJ, Bernstein LH, Boley SJ, Frank MS: Metronidazole therapy for perianal Crohn's disease: a followup study. Gastroenterology 1982;83:383-387.

28 Jakobovits J, Schuster MM: Metronidazole therapy for Crohn's disease and associated fistulae. Am J Gastroenterol 1984;79:533-540.

29 Turunen U, Farkkila M, Seppala K: Long-term treatment of peri-anal or fistulous Crohn's disease with ciprofloxacin. Scand J Gastronterol 1989;24(suppl 48):144.

30 Wolf J: Ciprofloxacin may be useful in Crohn's disease. Gastroenterology 1990;98:A212(abstract).

31 Solomon M, McLeod R, O’Connor B, Steinhart A, Greenberg G, Cohen Z: Combination ciprofloxacin and metronidazole in severe perianal Crohn's disease. Can J Gastroenterol 1993;7:571-573.

32 Thia KT, Mahadevan U, Feagan BG, Wong C, Cockeram A, Bitton A, Bernstein CN, Sandborn WJ: Ciprofloxacin or metronidazole for the treatment of perianal fistulas in patients with Crohn's disease: a randomized, double-blind, placebo-controlled pilot study. Inflamm Bowel Dis 2009;15:17-24.

33 McDonald JW, Feagan BG, Jewell D, Brynskov J Stange EF, Macdonald JK: Cyclosporine for induction of remission in Crohn's disease. Cochrane Database Syst Rev 2005;18:CD000297.

34 Present DH, Lichtiger S: Efficacy of cyclosporine in treatment of fistula of Crohn's disease. Dig Dis Sci 1994;39:374-380.

35 Egan LJ, Sandborn WJ, Tremaine WJ: Clinical outcome following treatment of refractory inflammatory and fistulising Crohn's disease with intravenous cyclosporine. Am J Gastroenterol 1998;93:442-448.

36 Hanauer SB, Smith MB: Rapid closure of Crohn's disease fistulas with continuous intravenous cyclosporine. Am J Gastroenterol 1993;88:646-649.

37 Nakase H, Yoshino T, Matsuura M: Role of calcineurin inhibitors for inflammatory bowel disease in biologics era: when and how to use. Inflamm Bowel Dis 2014;20: 2151-2156.

38 Sandborn WJ, Present DH, Isaacs KL, Wolf DC Greenberg E, Hanauer SB, Feagan BG, Mayer L, Johnson T, Galanko J, Martin C, Sandler RS: Tacrolimus for the treatment of fistulas in patients with Crohn's disease: a randomized, placebo-controlled trial. Gastroenterology 2003;125:380-388.

39 González-Lama Y, Abreu L, Vera MI, Pastrana M, Tabernero S, Revilla J, Durán JG, Escartin P: Long-term oral tacrolimus therapy in refractory to infliximab fistulizing Crohn's disease. Inflamm Bowel Dis 2005;11:8-15. 
40 Bär F, Sina C, Fellermann K: Thiopurines in inflammatory bowel disease revisited. World J Gastroenterol 2013;19:1699-1706.

41 Pearson DC, May GR, Fick GH, Sutherland LR: Azathioprine and 6-mercaptopurine in Crohn's disease: a meta-analysis. Ann Intern Med 1995;123:132-142.

42 Present DH, Korelitz BI, Wisch N, Glass JL, Sachar DB, Pasternack BS: Treatment of Crohn's disease with 6-mercaptopurine: a long-term, randomized, doubleblind study. N Eng J Med 1980;302:981-987.

43 Present DH, Rutgeerts P, Targan S, Hanauer SB, Mayer L, van Hogezand RA, Podolsky DK, Sands BE, Braakman T, DeWood KL, Schaibl TF, van Deventer SJ: Infliximab for the treatment of fistulas with Crohn's disease. N Engl J Med 1999;340:1398-1405.

44 Sands BE, Anderson FH, Bernstein CN, Chey WY, Feagan BG, Fedorak RN, Kamm MA, Korzenik JR, Lashner BA, Wild G, Wolf DC, Marsters PA, Travers SB, Blank MA, van Deventer SJ: Infliximab maintenance therapy for fistulizing Crohn's disease. N Engl J Med 2004;350:876-885.

45 Sands BE, Blank MA, Diamond RH, Barrett JP, van Deventer SJ: Maintenance infliximab does not result in increased abscess development in fistulizing Crohn's disease: results from the ACCENT II study. Aliment Pharmacol Ther 2006;23:1127-1136.

46 Colombel JF, Sandborn WJ, Rutgeerts P, Enns R, Hanauer SB, Panaccione R, Schreiber S, Byczkowski D, Li J, Kent JD, Pollack PF: Adalimumab for maintenance of clinical response and remission in patients with Crohn's disease: the CHARM trial. Gastroenterology 2007;132:52-65.
47 Lichtiger S, Binion DG, Wolf DC, Present DH, Bensimon AG, Wu E, Cardoso AT, Chao J, Mulani PM, Lomax KG, Kent JD: The CHOICE trial: adalimumab demonstrates safety, fistula healing improved quality of life and increased work productivity in patients with Crohn's disease who failed prior to infliximab therapy. Aliment Pharmacol Ther 2010;32:1228-1239.

48 Hanauer SB, Sandborn WJ, Rutgeerts P, Fedorak RN, Lukas M, MacIntosh D, Panaccione R, Wolf D, Pollack $P$ : Human anti-tumor necrosis factor monoclonal antibody (adalimumab) in Crohn's disease: the CLASSIC-I trial. Gastroenterology 2006;130:323-333.

49 Sandborn WJ, Rutgeerts P, Enns R, Hanauer SB, Colombel JF, Panaccione R, D’Haens G, Li J, Rosenfeld MR, Kent JD, Pollack PF: Adalimumab induction therapy for Crohn disease previously treated with infliximab: a randomized trial. Ann Intern Med 2007;146: 829-838.

50 Sandborn WJ, Feagan BG, Stoinov S, Honiball PJ, Rutgeerts P, Mason D, Bloomfield R, Schreiber S: Certolizumab pegol for the treatment of Crohn's disease. $\mathrm{N}$ Engl J Med 2007;357:228-238.

51 Schreiber S, Khaliq-Kareemi M, Lawrance IC, Thomson O, Hanauer SB, McColm J, Bloomfield R, Sandborn WJ: Maintenance therapy with certolizumab pegol for Crohn's disease. N Engl J Med 2007;357:239-250.

52 Schreiber S, Lawrance IC, Thomsen OØ, Hanauer SB, Bloomfield R, Sandborn WJ: Randomised clinical trial: certolizumab pegol for fistulas in Crohn's disease subgroup results from a placebo-controlled study. Aliment Pharmacol Ther 2011;33:185-193.
53 West RL, van der Woude CJ, Hansen BE, Felt-Bersma RJ, van Tilburg AJ, Drapers JA, Kuipers J: Clinical and endosonographic effect of ciprofloxacin on the treatment of perianal fistulae in Crohn's disease with in fliximab: a double-blind placebo-controlled study. Aliment Pharmacol Ther 2004;20:1329-1336.

54 Dewint P, Hansen BE, Verhey E, Oldenburg B, Hommes DW, Pierik M, Ponsioen CI, van Dullemen HM, Russel M, van Bodegraven AA, van der Woude CJ: Adalimumab combined with ciprofloxacin is superior to adalimumab monotherapy in perianal fistula closure in Crohn's disease: a randomised, doubleblind, placebo controlled trial (ADAFI). Gut 2014;63: 292-299.

55 Dejaco C, Harrer M, Waldhoer T, Miehsler W, Vogelsang $\mathrm{H}$, Reinisch W: Antibiotics and azathioprine for the treatment of perianal fistulas in Crohn's disease. Aliment Pharmacol Ther 2003;18:1113-1120.

56 Tozer P, Ng SC, Siddiqui MR, Plamondon S, Burling D, Gupta A, Swatton A, Tripoli S, Vaizey CJ, Kamm MA, Phillips R, Hart A: Long-term MRI-guided combined anti-TNF-a and thiopurine therapy for Crohn's perianal fistulas. Inflamm Bowel Dis 2012;18:1825-1834.

57 Poole R: Vedolizumab: first global approval. Drugs 2014;74:1293-1303. 